\title{
Improving the Anticorrosion Characteristics of Polymer Coatings in the Case of Their Modification with Compositions Based on Organosilanes
}

\author{
M. A. Petrunin ${ }^{a}$, N. A. Gladkikh ${ }^{a}$, M. A. Maleeva ${ }^{a}$, A. A. Rybkina ${ }^{a}$, E. V. Terekhova ${ }^{a}$, \\ T. A. Yurasova ${ }^{a}$, V. E. Ignatenko ${ }^{a}$, L. B. Maksaeva ${ }^{a}, *$, V. A. Kotenev ${ }^{a}$, and A. Yu. Tsivadze ${ }^{a}$ \\ ${ }^{a}$ Frumkin Institute of Physical Chemistry and Electrochemistry, Moscow, 119071 Russia \\ *e-mail:Imaksaeva@mail.ru
}

Received June 15, 2020; revised June 22, 2020; accepted June 29, 2020

\begin{abstract}
The effect of a series of organosilanes and their mixtures with corrosion inhibitors on the anticorrosion properties of polymer and paint coatings on steel, namely, on the adhesive characteristics of the coatings and corrosion behavior of the metal in the presence of coatings modified with organosilanes, corrosion inhibitors, and their mixtures, is studied. It is shown that mixtures of 1,2,3-benzotriazole (BTA) with vinyltrimethoxysilane (VTMS) or aminoethylaminopropyltrimethoxysilane-diaminosilane (DAS) inhibit the local dissolution and underfilm corrosion of carbon steel, and the potential of local depassivation shifts by $0.3-0.4 \mathrm{~V}$. Here, compact polymer-like layers that are strongly bound to the metal surface are formed on the surface of steel. Corrosion and mechanical tests of the samples of pipe steels with different types of inhibiting compositions are conducted. The effect of the inhibitors on the crack growth under static loading in a model soil electrolyte ( $\mathrm{pH}$ of 5.5) and on the crack resistance of steel under slow tension in an NS-4 model underfilm electrolyte (pH of 7.0) is evaluated. The tests are performed in media free from and containing hydrogen sulfide. It is shown that the best inhibiting properties are manifested by the mixtures of corrosion inhibitors with organosilanes. Comparative laboratory and bench tests for the adhesive strength, water resistance, and resistance to cathodic detachment of the adhesive junctions obtained upon applying the modified polymer and paint coatings onto the surface of steel are performed. It is found that introducing a mixture of organosilane and a corrosion inhibitor improves the adhesive properties of polymer and paint coatings.
\end{abstract}

DOI: $10.1134 / \mathrm{S} 2070205121020076$

\section{INTRODUCTION}

Currently, the corrosion of metallic structures is an important global problem, and the reduction of the losses as a result of corrosion becomes one of the most important tasks in industrially developed countries because these losses are estimated at huge financial costs. Thus, in 2001, the total annual expenditures for corrosion prevention and corrosion damage control in the United States reached $\$ 276$ billion per annum, which is equivalent to $3.1 \%$ of the GNP [1]. According to the data of the World Corrosion Organization, the annual global expenditures on corrosion were $\$ 552$ billion in 2008 [2] and increased to $\$ 2.5$ trillion in 2013, which exceeds $3 \%$ of the global GDP [3]. According to some data, the total expenditures for corrosion are currently $3-6 \%$ of GDP in some developed countries [4] and are continuing to grow.

A significant part of the expenditures goes to the prevention, and damage control of the consequences, of corrosion in the oil and gas industry. Thus, e.g., the losses during the failures at the gas and oil lines were $\$ 7$ billion in 2001 in the United States, while they were $\$ 2.2$ billion in the oil and gas extraction and process- ing industry overall [1]. The incident statistics in the gas pipeline system of OAO Gazprom and global experience in the operation of high-pressure gas pipelines evidences that the corrosion of the outer surface of the pipes is one of the main reasons for the incapacitation of underground pipelines [5]. The problem of preventing corrosion-in particular, of dangerous types, such as stress corrosion cracking (SCC) of the outer wall of pipelines [6]-remains important despite some progress that has been made in solving many organizational and technical issues associated with decreasing the risk of failures due to SCC [7].

On the other hand, experts suppose that using modern methods of corrosion control and anticorrosion protection will make it possible to reduce corrosion expenditures by $20-25 \%[1,8]$.

In view of the above, it is apparent that the development of efficient methods of metal corrosion prevention is currently an important science and technology objective.

One of the most efficient methods of corrosion prevention is the protection of metals with paint and polymer coatings [9], which have been successfully 
Table 1. Chemical composition of the steel of the X70 strength class under study

\begin{tabular}{l|c|c|c|c|c|c|c|c|c|c|c|c|c|c|c}
\hline & $\mathrm{C}$ & $\mathrm{Si}$ & $\mathrm{Mn}$ & $\mathrm{S}$ & $\mathrm{P}$ & $\mathrm{Cr}$ & $\mathrm{Ni}$ & $\mathrm{Cu}$ & $\mathrm{Al}$ & $\mathrm{N}$ & $\mathrm{V}$ & $\mathrm{Ti}$ & $\mathrm{Nb}$ & $\mathrm{Mo}$ & $\mathrm{Ca}$ \\
\hline Min & 0.07 & 0.15 & 1.05 & & & & 0.09 & 0.08 & 0.02 & & 0.035 & 0.015 & 0.02 & 0.05 & \\
Max & 0.10 & 0.35 & 1.20 & 0.004 & 0.012 & 0.10 & 0.19 & 0.18 & 0.05 & 0.008 & 0.050 & 0.030 & 0.04 & 0.1 & 0.005 \\
\hline
\end{tabular}

applied for many years and are continued to be used for anticorrosion protection of metallic structures [10]. However, it is known $[9,11]$ that the protective properties of polymer coatings are to a significant extent determined by the strength and stability of the adhesion bonds at the metal/polymer interface. Because of this, another important science and technology objective is the development of the methods for improving the adhesive characteristics of protective coatings. In practice, preliminary (prior to applying the coating) treatment of the surface is often applied in the case of the use of paint and polymer coatings on metals for improving the adhesion and anticorrosion properties of the coating. One of the most widely used methods of such a pretreatment is "local chemical oxidation" with a composition based on chromium(VI) compounds (chromating) [12]. This method does not conform to modern environmental requirements [13]. In addition, chromating is prohibited for use in some countries and will be subject to absolute prohibition in the long run [14]. In connection with this, a need for developing more efficient and environmentally friendly methods of preliminary treatment of metallic surfaces emerged late in the 20th century in the global practice of anticorrosion protection, which attracted the attention of researchers [15]. However, despite the large number of studies devoted to the replacement of chromate coatings (chromate-free surface treatment), no environmentally friendly process for the pretreatment of a metallic surface capable of replacing chromating has been proposed.

Organosilanes $\left(\mathrm{R}_{n} \mathrm{Si}\left(\mathrm{OC}_{2} \mathrm{H}_{5}\right)_{4-n}\right)$, or so-called "silane adhesion promoters, dressings, or silane coupling agents" [16], are environmentally friendly compounds that, being adsorbed on the surface of metals, form surface self-organizing siloxane nanolayers [17-19] and have been successfully used for increasing the adhesion of a polymer binding agent to the surface of an inorganic filler in composite materials for several decades [20]. During the adsorption of organosilanes and formation of surface nanolayers, on the one hand, strong and hydrolytically stable $\mathrm{Me}-\mathrm{O}-\mathrm{Si}$ bonds with the hydroxylated metal surface are formed, and, on the other hand, the organic radicals of the silane molecules are capable of interacting with the components of a polymer or paint coating, thus providing a high affinity of the surface nanolayer for a wide range of polymer and paint materials. Various functional groups can be introduced into the organic radical $(R)$, varying them depending on the nature of the polymer of the coating to provide the maximum affinity of the surface layer and the coating, which was widely used during the development of composite materials for increasing the adhesion of a polymer binding agent to the surfaces of inorganic fillers in composite materials $[16,20]$. In addition, the formation of surface nanolayers based on environmentally friendly organosilanes is capable of inhibiting the corrosion of structural metals [17-19, 22] and successfully competing with and, in the long run, replacing the chromating of metals $[21,23]$.

The aim of this work consisted in

(a) an investigation of the effect of organosilanes and their mixtures with corrosion inhibitors on the anticorrosion properties of polymer and paint coatings on steel, namely, on the adhesive characteristics of the coatings and corrosion behavior of the metal in the presence of coatings modified with organosilanes, corrosion inhibitors, and their mixtures; and

(b) the development of an optimum method for modifying the coatings by introducing modifiers into the bulk of the polymer coating for increasing the adhesion of the coating and decelerating the corrosion of steel in the case of violation of the integrity of the coating or its detachment.

\section{STUDY PROCEDURE}

Samples fabricated from pipe steel of the X70 strength class (Table 1) and steels of brands $08 \mathrm{kp}$ and St3 (Tables 2, 3) were used in this work. The following organosilanes (OOO Penta, Russia) were used for the modification of the coatings:

1. Vinyltrimethoxysilane (VTMS)

$$
\mathrm{CH}_{2}=\mathrm{CH}-\mathrm{Si}\left(\mathrm{OCH}_{3}\right)_{3}
$$

2. Aminopropyltriethoxysilane (AGM)

$$
\mathrm{NH}_{2}=\left(\mathrm{CH}_{2}\right)_{3}-\mathrm{Si}\left(\mathrm{OC}_{2} \mathrm{H}_{5}\right)_{3}
$$

3. Methacryloxypropyltrimethoxysilane (MPTMS)

$$
\mathrm{CH}_{3}-\mathrm{CH}\left(\mathrm{CH}_{2}\right)-\mathrm{C}(\mathrm{O})-\mathrm{CH}_{2}-\mathrm{CH}_{2}-\mathrm{CH}_{2}-\mathrm{Si}\left(\mathrm{OCH}_{3}\right)_{3}
$$

4. Aminoethylaminopropyltrimethoxysilane-diaminosilane (DAS)

$$
\mathrm{NH}_{2}-\mathrm{CH}_{2}-\mathrm{CH}_{2}-\mathrm{NH}-\mathrm{CH}_{2}-\mathrm{CH}_{2}-\mathrm{CH}_{2}-\mathrm{Si}\left(\mathrm{OCH}_{3}\right)_{3}
$$


Table 2. Chemical composition of the steel of the St 3 brand under study

\begin{tabular}{|c|c|c|c|c|c|c|c|}
\hline \multicolumn{8}{|c|}{ Weight fraction of chemical elements, $\%$} \\
\hline $\mathrm{C}$ & Mn & $\mathrm{Si}$ & $\mathrm{Cr}$ & $\mathrm{Ni}$ & $\mathrm{Cu}$ & $\mathrm{S}$ & $\mathrm{P}$ \\
\hline $0.14-0.22$ & $0.3-0.6$ & $<0.05$ & $<0.05$ & $<0.05$ & $<0.05$ & $<0.05$ & $<0.04$ \\
\hline
\end{tabular}

Table 3. Chemical composition of the steel of the $08 \mathrm{kp}$ brand under study

\begin{tabular}{|c|c|c|c|c|c|c|c|}
\hline \multicolumn{8}{|c|}{ Weight fraction of chemical elements, $\%$} \\
\hline $\mathrm{C}$ & Mn & $\mathrm{Si}$ & $\mathrm{Cr}$ & $\mathrm{Ni}$ & $\mathrm{Cu}$ & $\mathrm{S}$ & $\mathrm{P}$ \\
\hline $0.05-0.12$ & $0.3-0.6$ & $<0.03$ & $<0.1$ & $<0.15$ & $<0.15$ & $<0.004$ & $<0.0035$ \\
\hline
\end{tabular}

\section{Bis(triethoxysilyl)ethane (BTESE)}

$$
\left(\mathrm{C}_{2} \mathrm{H}_{5} \mathrm{O}\right)_{3} \mathrm{Si}-\mathrm{CH}_{2}-\mathrm{CH}_{2}-\mathrm{Si}\left(\mathrm{OC}_{2} \mathrm{H}_{5}\right)_{3} \text {. }
$$

In addition, the following corrosion inhibitors were used:

- octadecylamine $\mathrm{C}_{18} \mathrm{H}_{37} \mathrm{NH}_{2}$ (OOO Konferum, Russia) (ODA); and

- 1,2,3-benzotriazole $\mathrm{C}_{6} \mathrm{H}_{5} \mathrm{~N}_{3}$ (OOO Predpriyatie ROD, Russia) (BTA) (Fig. 1).

The following polymer and paint coatings were used in this work:

(1) a bitumen-polymer coating (BPC) of Dekom brand (OOO Delan, Russia) consisting of a bitumenpolymer primer, a reinforced mastic, and a polymer tape; and

(2) a paint coating (PLC): a Lacryl water-soluble styrene-acrylic dispersion of 9930 brand (Entod Pharmaceuticals Limited, India).

The effect of the organosilicon surface nanolayers on the electrochemical behavior of steel was studied by a polarization method [24, 25]. A three-electrode cell with separated electrode spaces was used, and the potential was measured relative to a silver/silver chloride $(\mathrm{Ag} / \mathrm{AgCl})$ reference electrode and recalculated for the normal hydrogen electrode (NHE) scale. The measurements were potentiostatically (at fixed potentials) or potentiodynamically (at the potential sweep rate of $0.1 \mathrm{mV} / \mathrm{s}$ ) performed using an IPC-Pro potentiostat (Russia). Steel electrodes of three types were used as the sample: disc $\left(0.8 \mathrm{~cm}^{2}\right)$, cylindrical $\left(12.14 \mathrm{~cm}^{2}\right)$, and rectangular (a length of $15 \mathrm{~mm}$, a width of $12 \mathrm{~mm}$, a thickness of $0.3 \mathrm{~mm}$ ). A platinum plate with an area of $1 \mathrm{~cm}^{2}$ and a thickness of $1.2 \mathrm{~mm}$ acted as the auxiliary electrode.

Critical pitting potential $E_{\mathrm{pt}}$ (or potential of local depassivation of steel), i.e., the potential, above which pitting dissolution of the metal occurs and stable pit-

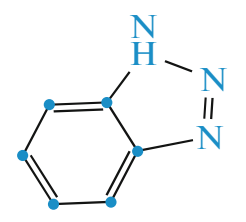

Fig. 1. Structural formula of 1,2,3-benzotriazole (BTA). tings are formed, was determined from the anodic polarization curves by the breaking point in the curve as a potential, upon reaching which a sharp increase in the current was observed [26]. The criterion of inhibiting activity of organosilane was the value of the shift of $E_{\mathrm{pt}}$ toward positive values [27]:

$$
\Delta E_{\mathrm{pt}}=E_{\mathrm{pt}-\bmod }-E_{\mathrm{pt}-\mathrm{bgd}},
$$

where $E_{\mathrm{pt}-\text { mod }}$ and $E_{\mathrm{pt}-\mathrm{bgd}}$ are the values of the pitting potential in the presence and absence of the modifying additive, respectively.

Corrosion studies were performed by the method of accelerated corrosion testing in an MHK-408CL climatic chamber (Taiwan) at a relative humidity RH of $95 \%$ and $t=60^{\circ} \mathrm{C}$. Samples made of steel foil of steel of $08 \mathrm{kp}$ brand (the composition is presented in Table 3) with an area of $9 \mathrm{~cm}^{2}$ and a thickness of $100 \mu \mathrm{m}$ were tested. The value of the corrosion of steel was gravimetrically determined by the difference of the weight of the samples before and after tests by weighing the samples before the tests and after removing the corrosion products from the samples after the tests. The corrosion products were removed from the surface of the samples upon the completion of the tests by standard procedures [29]. In addition, the degree of corrosion damage of the painted samples was evaluated in accordance with the requirements of the international standard [30].

The polymer coatings were modified as follows:

(a) in the case of a PLC, the modifier (silane, an inhibitor, or a mixture) additive was dissolved in the required amount in a mixture of water and chloroform (10\% chloroform) and dispersed by ultrasound (in a Sapfir-08 TTs ultrasonic bath, Russia) until complete dissolution of the modifier. The obtained solution was introduced into the dispersion; and

(b) in the case of a BPC, the modifier(s) was(were) introduced in the required amount into the bulk of the polymer (primer) and mechanically stirred for $3 \mathrm{~h}$. BTA was dissolved in isopropanol prior to introducing into the PLC, while ODA was dissolved in toluene prior to introducing into the BPC. The concentration of both organosilane and each of the corrosion inhibitors in the coating was $5 \mathrm{mM}$.

When applying the polymer and paint coatings, plates made of steel with a size of $100 \times 150 \times 3 \mathrm{~mm}$ were used, onto the working section of which the modified bitumen-polymer primer or PLC was 


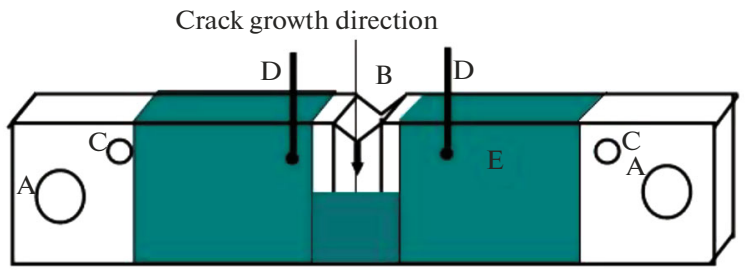

Fig. 2. Scheme of the beam sample for studying the rate of crack growth: (A) holes for the fixation in the tensile testing machine, (B) stress concentrator, (C) screw holes for current leads, (D) contacts for measuring the potential, and (E) chemically resistant lacquer.

applied. In the case of the BPC, a strip of a reinforced bitumen-polymer mastic was glued onto the primer, atop which a polymer tape was applied. The consumption of the primer was $300 \mathrm{~g} / \mathrm{m}^{2}$. The thickness of the coating was determined with an EASY-CHECK FN thickness gauge (Germany). The total thickness of the structure of the coatings was $2.81 \pm 0.05$ and $0.1 \pm$ $0.01 \mathrm{~mm}$ for the BPC and PLC, respectively.

The following test solutions were used when carrying out the electrochemical and corrosion studies.

- A mixture of a synthetic soil electrolyte (a socalled "NS-4 solution" [30]) and a borate buffer solution $\left(0.4 \mathrm{M} \mathrm{H}_{3} \mathrm{BO}_{3}+0.01 \mathrm{M} \mathrm{Na}_{2} \mathrm{~B}_{4} \mathrm{O}_{7}\right)$ with the value of $\mathrm{pH}$ of 7.0.

The composition of an NS-4 solution was as follows: $1.64 \mathrm{mM} \mathrm{KCl}+5.75 \mathrm{mM} \mathrm{NaHCO}{ }_{3}+1.23 \mathrm{mM}$ $\mathrm{CaCl}_{2}+0.74 \mathrm{mM} \mathrm{MgSO}_{4}$.

- A mixture of a borate buffer solution $(0.4 \mathrm{M}$ $\left.\mathrm{H}_{3} \mathrm{BO}_{3}+0.1 \mathrm{M} \mathrm{Na}_{2} \mathrm{~B}_{4} \mathrm{O}_{7}\right)(\mathrm{pH}$ of 6.7$)$ and an NS-4 electrolyte with the addition of $0.001 \mathrm{M} \mathrm{Na}_{2} \mathrm{~S} \cdot 10 \mathrm{H}_{2} \mathrm{O}$.

- An aqueous extract from the bitumen-polymer primer.

A modified primer was used for the preparation of the aqueous extracts. The primer was preliminarily dried in air, ground, and placed into a solution of buffered soil electrolyte at room temperature. The extraction time for the preparation of the aqueous extract was 7-91 days.

All the chemicals and solvents were of reagent grade.

The corrosion and mechanical tests were performed by two methods.

(1) Static loading [31, 32].

Beam samples with a size of $200 \times 15 \times 3 \mathrm{~mm}$ with a preliminarily grown fatigue crack with a depth of $7 \mathrm{~mm}$ [31] (Fig. 2), which were fixed in the electrochemical cell with the test solution, were used for static tests (Fig. 3).

A constant tensile load of 500-1500 kg was applied to the samples onto the gross cross-section using a VEB tensile testing machine (Germany), and the change in their electrical resistance was measured. The scheme of the unit is presented in Fig. 4. The duration of the tests was 5 to 14 days. The experiments

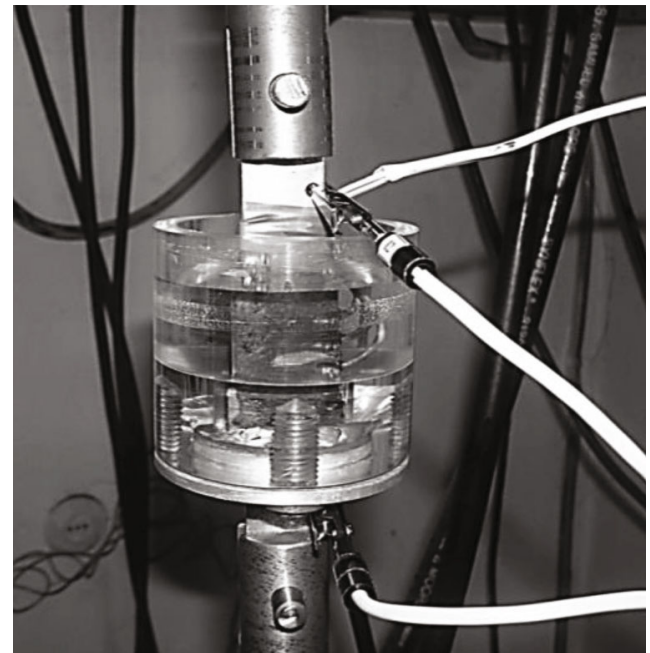

Fig. 3. Corrosion and mechanical tests of pipe steel by static loading. The beam sample in the testing cell.

were performed at room temperature and with free access of air. The test solution was periodically (after $2-3$ days) replaced. The potentials were measured relative to a silver/silver chloride reference electrode and recalculated for the normal hydrogen electrode scale. To determine the rate of the crack growth, a method of measurement of the electrical resistance of the sample was applied [33]. The resistance of the sample was measured by a BSZ-010-2 microohmmeter (Russia) by a four-wire scheme with the accuracy of $10^{-8} \Omega$.

The rate of the growth was calculated by the formula

$$
V=\frac{\Delta l}{t}
$$

where $\Delta l$ is the length increment of the crack, mm and $t$ is the time of the tests, days.

The length increment of the crack was determined as

$$
\Delta l=d_{0}\left(1-\frac{R_{0}}{R}\right)
$$

where $d_{0}$ is the initial width of the sample, $\mathrm{mm}$, and $R_{0}$ and $R$ are the initial and measured at a time point $\tau$ resistances, respectively, $\Omega$.

(2) Slow strain rate test (SSRT) [34, 35].

Slow strain rate tests (SSRTs) were performed on cylindrical samples in accordance with [35]. The appearance of the samples is presented in Fig. 5. The geometric sizes are presented in Table 4. The samples were mechanically treated using modes excluding the overheating and cold hardening in the working part.

Mechanical treatment of the samples was performed in the modes excluding the overheating and cold hardening in the working part. No more than $0.05 \mathrm{~mm}$ was taken off over the last two runs. The working part of the samples was polished lengthways; sand paper of the 0 brand was used for the final treatment. The value of the roughness of the working surface of the samples $\left(R_{\mathrm{a}}\right)$ was $1.25 \mu \mathrm{m}$. A wire was soldered to one of the 


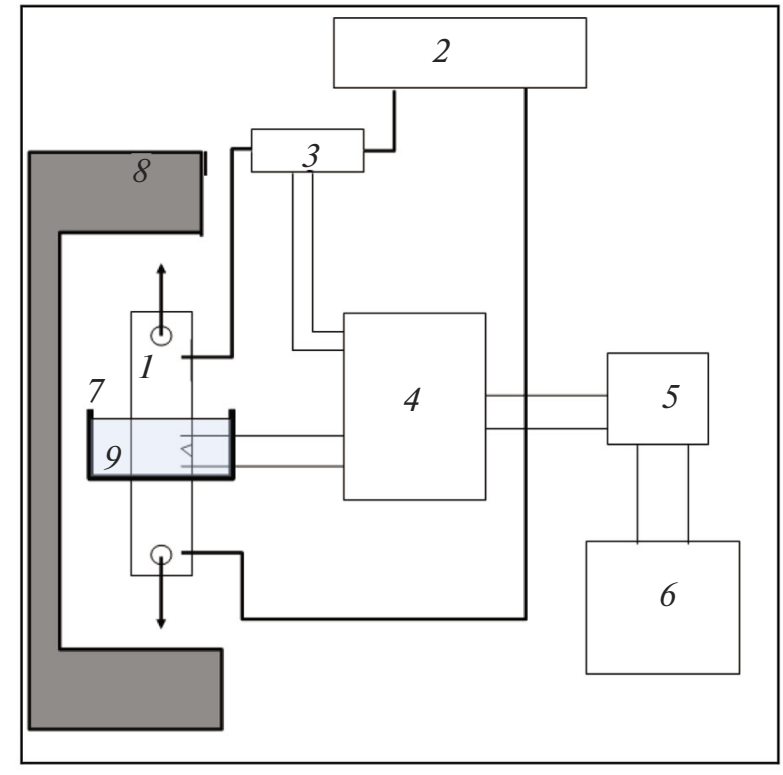

Fig. 4. Scheme of the unit for measuring the rate of crack growth by static loading: (1) sample with a crack, (2) current stabilizer, (3) reference resistance, (4) measuring bridge, (5) photoelectric amplifier, (6) event recorder, (7) three-electrode electrochemical cell, $(8)$ tensile testing machine, and (9) working electrolyte.

ends of the sample to measure the potential. The surface of the samples was degreased with acetone and covered with a chemically resistant lacquer except for the middle thin working part.

The measurement of the sizes of the samples over the working part before the test was performed with an error of up to $0.1 \mathrm{~mm}$ in at least three points: in the middle part and at the boundaries of the working length. The smallest of the working values was taken as the initial area of the cross section of the sample in its working part $\left(S_{0}\right)$.

The initial calculated value of $l_{0}$ was confined on the working length by marks with an error of up to $1 \%$. The marks were applied using dividing machines or manually using a metallic ruler.

Prior to the test, the samples were degreased with an organic solvent and rinsed with distilled water.

The samples were fixed in the grips of a HYBER $\mathrm{AB}$ brand tensile testing machine (Germany) and immersed into the test solution together with the grips (the scheme of the unit is presented in Fig. 6).

The samples were subjected to slow tension at a constant speed of $2 \times 10^{-6}$ to $1 \times 10^{-4} \mathrm{~mm} / \mathrm{h}$ through a reduction gearbox. Upon the break of the sample, the test was finished, and the time to its fracture was recorded. The fractured samples were rinsed with dis- (a)

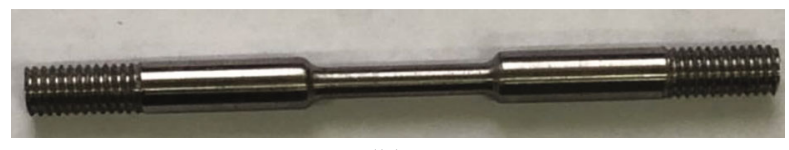

(b)

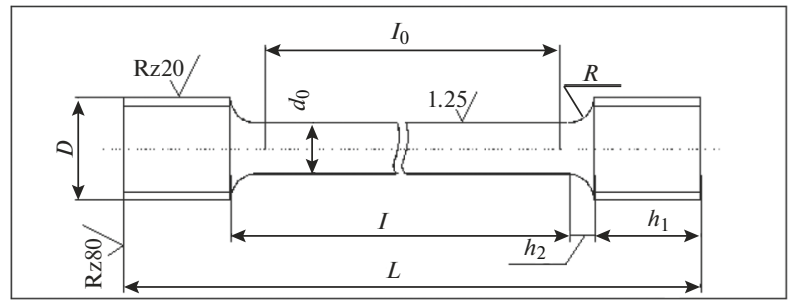

Fig. 5. Sample for carrying out the tests by the SSRT method: (a) the appearance of the sample and (b) the scheme of the sample corresponding to the normative requirements [36] for carrying out the tests by the SSRT method.

tilled water, dried in air, and placed into a desiccator for $48 \mathrm{~h}$, after which they were taken out, and the measurements for the determination of the geometry of the fractured sample and calculation of the elongation and contraction of the sample were conducted (Fig. 7).

The contraction after the break of the sample was calculated as

$$
R A=\frac{S_{0}-S_{k}}{S_{0}} \times 100 \%,
$$

where $S_{0}$ is the initial area of the cross section of the sample, $\mathrm{mm}^{2}$, and $S_{k}$ is the area of the cross section of the sample after the break, $\mathrm{mm}^{2}$.

To study the structure of the surface organosilane layer, steel samples were studied that were exposed in the solutions of the aqueous extract from the modified bitumen-polymer primer. The aqueous extract was obtained after the exposure of the primer in distilled water at room temperature for 50 days. A sample of pipe steel of X70 type with a size of $25 \times 15 \times 2 \mathrm{~mm}$ was immersed into the solution of the aqueous extract and kept for $10 \mathrm{~min}$, after which a reflection IR spectrum was recorded. Fourier-transform IR study of the surface of steel was performed using a Nicolet iN10 FT-IR Microscope Fourier-transform IR spectrometer (Thermo Fisher Scientific Inc., United States) in a range of $600-4000 \mathrm{~cm}^{-1}$ with a resolution of $4 \mathrm{~cm}^{-1}$ and number of scans of 400 . A mirror reflection accessory with an incidence angle of $80^{\circ}$ was used.

The control of the adhesion of the polymer composition was performed by the method of separation of the coating from the metal at an angle of $180^{\circ}$ in accordance with [37] on a Zwick/Roell Z010 tensile testing

Table 4. Sizes of the samples for the SSRT method in accordance with [36]

\begin{tabular}{c|c|c|c|c|c|c|c|c}
\hline & $d_{0}$ & $I_{0}=10 d_{0}$ & $I$ & $D$ & $h_{1}$ & $h_{2}$ & $R$ & $\mathrm{~L}$ \\
\hline Type 1 & 2.5 & 25 & $I_{0}+(0.5-2) d_{0}$ & M5 & 10 & 2.5 & 2.5 & $I+2\left(h_{1}+h_{2}\right)$ \\
\hline
\end{tabular}




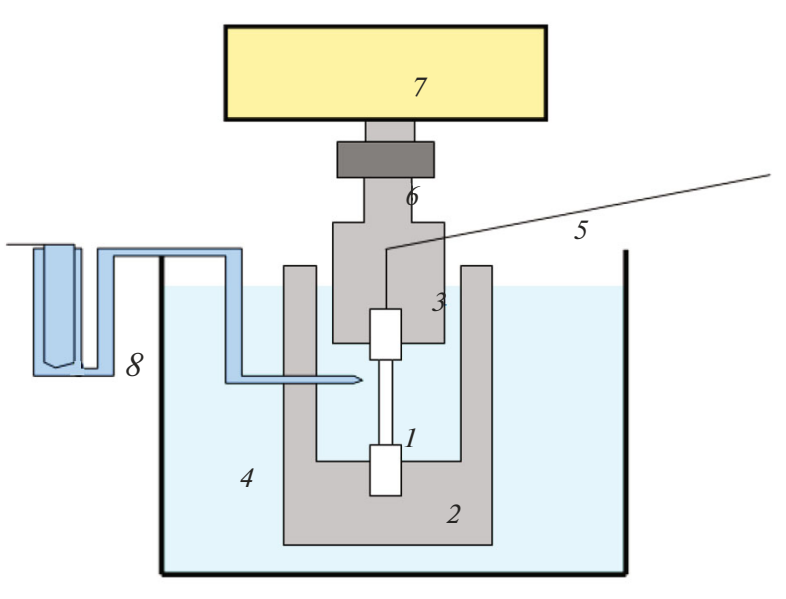

Fig. 6. Scheme of the unit for the slow tension of the sample: (1) sample, (2) immobile grip, (3) mobile grip, (4) vessel with the test solution, (5) output for measuring the potential, (6) dynamometer, (7) electric motor with a reducing valve, and $(8)$ salt bridge.

machine (Zwick GmbH \& Co. KG, Germany) using the samples shown in Fig. 8.

The adhesive strength, N/cm, was calculated by (4) according to [38, Annex K]:

$$
A=\frac{F}{B},
$$

where $F$ is the detachment strain on the section under control $(\mathrm{N})$, and $B$ is the width of the detachment strip, $\mathrm{cm}$.

The water resistance of adhesion was estimated in accordance with [37] by measuring the adhesion by the method of separation at an angle of $180^{\circ}$ after the exposure of the samples in water for $1000 \mathrm{~h}$ at $20 \pm 1{ }^{\circ} \mathrm{C}$.

Three samples of the same system were used in parallel when conducting the measurements of adhesion, and the separation force was calculated as the arithmetic mean value.

In addition to the laboratory adhesion studies, bench adhesion tests of the modified bitumen-polymer coating were performed on the bench of the manufacturer of the coating, OOO Delan, located in the Noginsk region of Moscow oblast. The bitumen- polymer coating was applied onto the surface of a section of a pipe (with a diameter of $1420 \mathrm{~mm}$ ) according to the technology used when carrying out the works on the field reinsulation of pipelines (Fig. 9) using both an unmodified primer and primers modified with organosilanes, a corrosion inhibitor, and their mixture. The pipe with the applied coating was left in air for 3 days, after which the adhesion of the coating was measured.

\section{RESULTS AND DISCUSSION}

The corrosion cracking of a metal is an electrochemical process, because of which one of the key factors affecting the crack origin and growth is the rate of the partial electrode reactions occurring on the surface of corroding steel $[6,39]$. Because of this, it is possible to evaluate the effect of organosilanes and corrosion inhibitors on the appearance and development of stress corrosion cracking based on the electrochemical data. Special attention was paid to studying the anode reaction because the mechanism of crack development on gas pipelines mainly occurs by the mechanism of local anodic dissolution [40]; in addition, it is known [26] that the sites of local dissolution (pittings) that appear during anodic polarization of a metal can act as the initiators of corrosion crack origin. One of the most studied heterocyclic metal corrosion inhibitors is 1,2,3-benzotriazole (BTA), which is widely used for the protection of nonferrous metals, including copper, against corrosion, and it has been shown in recent years that BTA is capable of efficiently passivating iron and low-carbon steel and inhibiting their pitting dissolution [27]. However, introducing BTA into the coating may lead to a decrease in the adhesive strength of the metal-polymer junction. To avoid or minimize this effect, adhesion promoters can be used together with BTA, the most efficient of which are organosilanes [17-19]. In addition, it has been found in recent years that the use of mixtures of organosilanes with corrosion inhibitors significantly increases the inhibiting capacity of the latter [28]. It can be expected that introducing a mixture of organosilane and BTA into the bulk of a polymer coating will make it possible to improve the anticorrosion characteristics of the coating without a decrease in the adhesion of the coating to the metal.
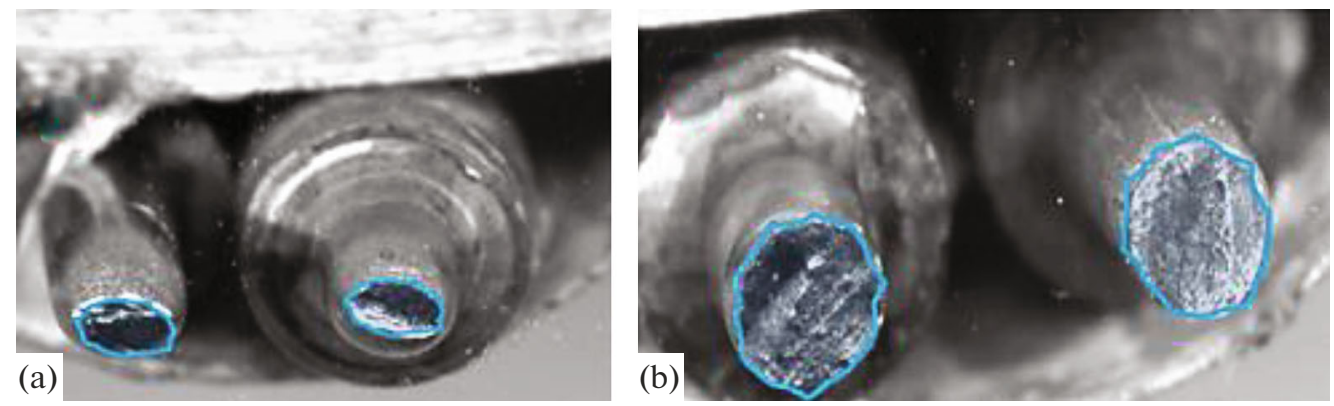

Fig. 7. Samples after SSRT tests with (a) large and (b) small contraction of the cross section of the sample. 


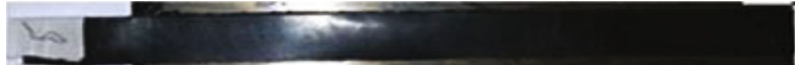

Fig. 8. Test sample for the control of the adhesion of the structure of the coating of the Dekom type by the method of detachment at an angle of $180^{\circ}$.

In connection with this, special attention was paid to studying the effect of organosilanes and corrosion inhibitors on the occurrence of the anode reaction of dissolution of steel. Organosilanes, BTA, ODA, and mixtures thereof were introduced into the background solution, and anodic polarization curves were recorded. The concentration of each component of the mixture (i.e., organosilanes, BTA, and/or ODA) was $5 \mathrm{mM}$. Figure 10 presents the potentiodynamic polarization curves of steel in the background solution (a borate buffer (BB) solution with the addition of $0.01 \mathrm{M} \mathrm{NaCl}$ ) with the additions of BTA and VTMS. As can be seen, peak current at $E=-0.45 \mathrm{~V}$ is observed in the polarization curve (Fig. 10) obtained in the background solution. Disruptive discharge of the passive film was observed at $E_{\mathrm{pt}}=-0.13 \mathrm{~V}$ (Fig. 10, curve 1). The addition of both BTA and organosilanes and their mixtures into the solution leads to the disappearance of the critical passivation current (Fig. 10, curves 2-4) and increase in the pitting potential by $0.15,0.10$, and $0.20 \mathrm{~V}$ for BTA, VTMS, and DAS, respectively (Fig. 10, Table 5). Table 5 presents the values of $\Delta E_{\mathrm{pt}}$ in the case of the use of the mixtures of various silanes with BTA.

A significant increase in the pitting potential was observed for all the studied mixtures (Fig. 10, curve 4; Table 5) both in comparison with the background solution and in the case of introduction of the individual components of the mixture into the background solution (i.e., individually BTA and organosilanes) (Fig. 10, curves 2,3). The maximum inhibiting effect was observed for the BTA + DAS mixture (Table 5).

The corrosion inhibiting action of organosilanes was earlier noted in the published sources [17-19, 21]. The authors associate the deceleration of the corrosion processes with the chemisorption of these compounds on the metal surface with the formation of $\mathrm{Me}-\mathrm{O}-\mathrm{Si}$ metal-siloxane bonds (reaction (5)) during the condensation of the silanol molecules which are the hydrolysis products of organosilanes [17-19] with the hydroxyl groups of the metal surface.

$$
\mathrm{R}-\mathrm{Si}(\mathrm{OH})_{3}+\mathrm{OH}-\mathrm{Me} \rightarrow \mathrm{R}-\mathrm{Si}(\mathrm{OH})_{2}-\mathrm{O}-\mathrm{Me} \text {. }
$$

It is known [27] that organic amines are efficient inhibitors of both equal-rate and local (including corrosion cracking [41]) corrosion including in the case of development of inhibited polymers [42].

Studying the electrochemical behavior of steel, the surface of which was modified with the solutions of ODA, organosilanes, and mixtures of organosilanes with ODA showed (Fig. 11) that the modification of the metal surface with both individual components of the mixtures and a mixture of the modifiers (organos-

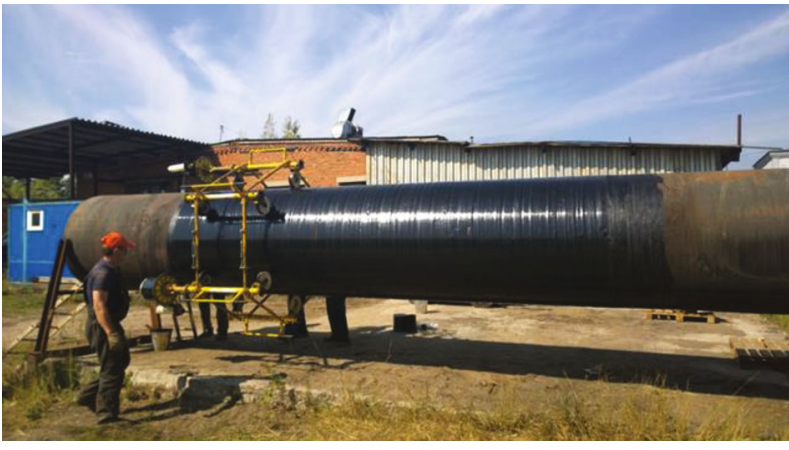

Fig. 9. Conduct of the bench adhesion tests at the testing ground of OOO Delan.

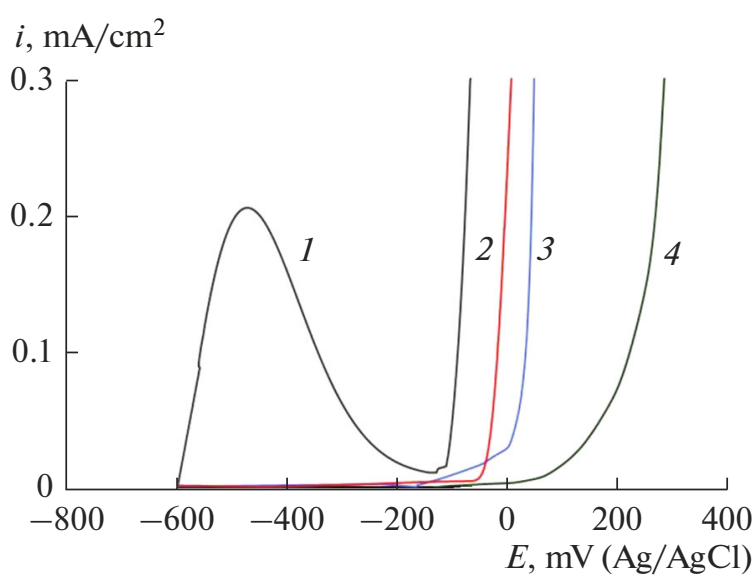

Fig. 10. Potentiodynamic curves of St 3 steel in the background solution and solution with additives: (1) background, (2) background $+5 \mathrm{mM}$ VTMS, (3) background + $5 \mathrm{mM}$ BTA, and (4) background + $5 \mathrm{mM}$ (VTMS + BTA). The potential sweep rate is $0.1 \mathrm{mV} / \mathrm{s}$.

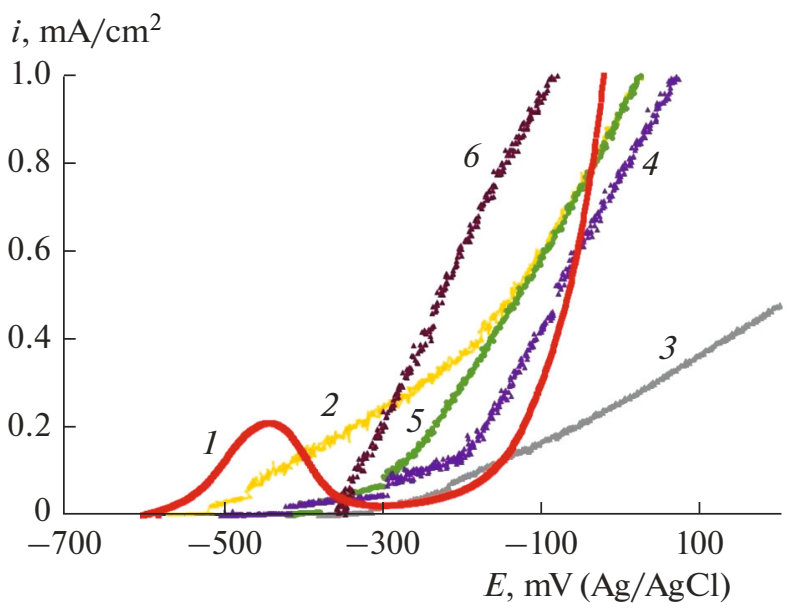

Fig. 11. Anodic potentiometric polarization curves obtained in a $0.1 \mathrm{M}$ solution of $\mathrm{NaCl}(\mathrm{pH}$ of 6.5$)$ at the potential sweep rate of $0.1 \mathrm{mV} / \mathrm{s}$ : (1) unmodified carbon steel and (2-6) steel modified with the toluene solutions with the additions of $(2,3)$ organosilanes: (2) $2 \%$ ODA and (3) $1 \%$ AGM and (4-6) their mixtures: (4) $2 \%$ ODA $+2 \%$ DAS, (5) $2 \%$ ODA + $1 \%$ AGM, and (6) $2 \%$ ODA $+1 \%$ $\mathrm{AGM}+1 \%$ VTMS. 


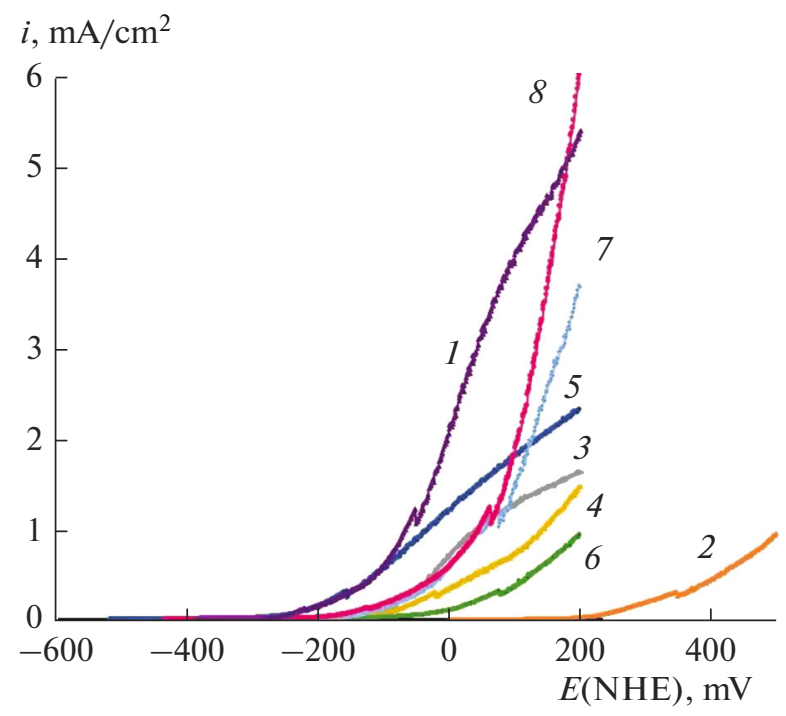

Fig. 12. Anodic polarization curves of steel obtained in a borate buffer solution ( $\mathrm{pH}$ of 6.5) with the addition of $0.001 \mathrm{M} \mathrm{NaCl}$ at the potential sweep rate of $0.1 \mathrm{mV} / \mathrm{s}:(1)$ the unmodified bitumen-polymer primer (BP) and (2-8) the BP modified with (2) $2 \%$ ODA, (3) 1\% VTMS, (4) $1 \%$ AGM, (5) $1 \%$ AGM + $1 \%$ VTMS, (6) $2 \%$ ODA $+1 \%$ VTMS, (7) $2 \%$ ODA + $1 \%$ AGM, and (8) $2 \%$ ODA + $1 \%$ VTMS $+1 \%$ AGM. The thickness of the layer of the primer is $0.2 \mathrm{~mm}$.

ilane and corrosion inhibitor) led to the inhibition of the equal-rate dissolution (up to the complete disappearance of the peak of the active-to-passive transition) and local dissolution of carbon steel (Fig. 11, curves $2-6$ ). For the studied modifying mixtures, the effect of deceleration is three- to sixfold on average.
The best result with respect to the inhibition of the rate of local dissolution is demonstrated by the treatment of the metal surface with a $1 \%$ toluene solution of AGM in toluene (Fig. 11, curve 3). The rate of local dissolution decreases 15-fold.

The anodic polarization curves recorded on the metallic samples, the surface of which was preliminarily treated with bitumen-polymer primers with different compositions (a thickness of $0.5-0.8 \mathrm{~mm}$ ), are presented in Fig. 12. The obtained results show that the presence of an unmodified coating (without the additions of organosilanes) on the metal surface leads to the passivation of the steel sample, and the absence of the peak of the active-to-passive transition of the metal (Fig. 12, curve 1), i.e., inhibition of the equal-rate dissolution of the metal and its passivation, is observed. The rate of dissolution of the metal from the pitting (characterized by the slope of the anodic curve after reaching $E_{\mathrm{pt}}$, Table 6 ) slightly changes. It is 0.013 and $0.014 \mathrm{~A} \mathrm{~V}^{-1} \mathrm{~cm}^{-2}$ for the steel with the coating and on the untreated surface, respectively. Introducing modifiers (ODA, organosilanes, and a mixture thereof) into the bitumen-polymer primer leads to both a shift of $E_{\mathrm{pt}}$ to the anode region (Fig. 12, curves 2-8) and a decrease in the rate of dissolution of the metal from the pitting (Table 6). This indicates that the modifiers inhibit both the process of occurrence of pittings and rate of their development. The values of the slopes of the sections of the anodic polarization curves in the range of potentials more positive than $E_{\mathrm{pt}}$ are presented in Table 6.

It is seen that the modification of the bitumenpolymer primer with organosilanes leads to the inhibition of the local dissolution of the metal. The modification of the coating with a $2 \%$ ODA $+1 \%$ VTMS mixture is the most efficient.

Table 5. Evaluation of the efficiency of the corrosion inhibiting mixtures by the change in $E_{\mathrm{pt}}$

\begin{tabular}{l|c|c}
\hline Composition of the solution and additive & $E_{\mathrm{pt}-\mathrm{mod}}, \mathrm{mV}(\mathrm{Ag} / \mathrm{AgCl})$ & $\Delta E_{\mathrm{pt}}, \mathrm{V} \mathrm{mV}(\mathrm{Ag} / \mathrm{AgCl})$ \\
\hline Background & -130 & 0 \\
BTA + VTMS & 107 & 237 \\
BTA + MPTMS & -17 & 113 \\
BTA + DAS & 311 & 441 \\
BTA + AGM & 114 & 244 \\
BTA + BTESE & -51 & 79 \\
\hline
\end{tabular}

Table 6. Values of pitting potentials $E_{\mathrm{pt}}$ and slopes of sections tan $\alpha$ of the anodic polarization curves (in the range of potentials more positive than $E_{\mathrm{pt}}$ ) of St3 carbon steel covered with a bitumen-polymer primer (BP)

\begin{tabular}{l|c|c}
\hline \multicolumn{1}{c|}{ Composition of the coating } & $E_{\text {pto }}(\mathrm{NHE}), \mathrm{mV}$ & $\tan \alpha, \mathrm{A} \mathrm{V}^{-1} \mathrm{~cm}^{-2}$ \\
\hline Steel without a coating & -250 & 0.014 \\
Steel + BP + 2\% ODA & -70 & 0.009 \\
Steel + BP + 1\% VTMS & -140 & 0.004 \\
Steel + BP + 1\% AGM & -110 & 0.006 \\
Steel + BP + 1\% VTMS +1\% AGM & -250 & 0.005 \\
Steel + BP + 2\% ODA + 1\% VTMS & -40 & 0.003 \\
Steel + BP + 2\% ODA + 1\% AGM & -170 & 0.008 \\
Steel + BP + 2\% ODA + 1\% VTMS + 1\% AGM & -190 & 0.012 \\
Steel covered with unmodified BP & -250 & 0.013 \\
\hline
\end{tabular}


(a)

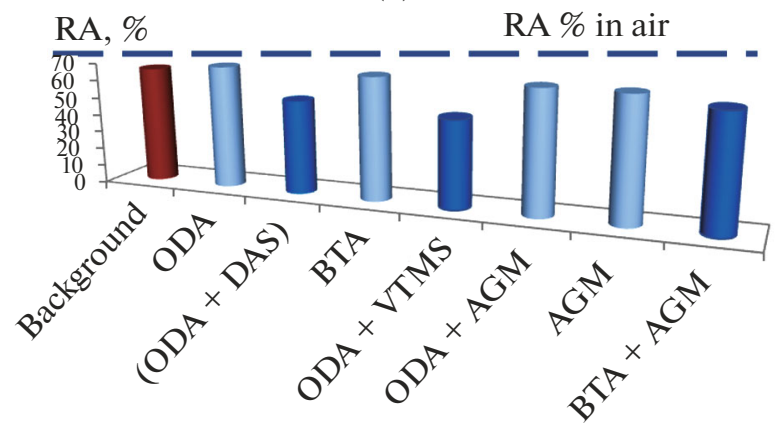

(b)

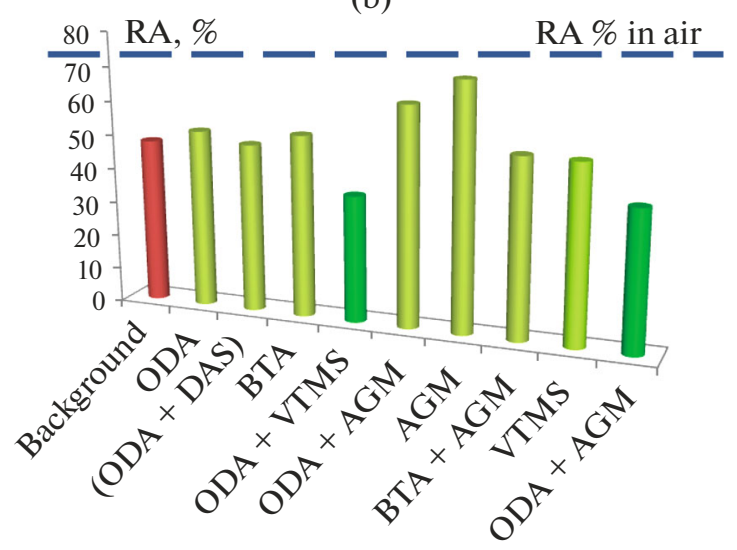

Fig. 13. Dependence of the value of the contraction of the sample of pipe steel in the case of the tests by SSRTs in the (a) NS-4 background medium + BB and (b) NS-4 background medium $+\mathrm{BB}+10 \mathrm{mM} \mathrm{Na}_{2} \mathrm{~S}$ with additions of the inhibitor systems.

Therefore, the study of the electrochemical behavior of steel showed that the surface modifiers (organosilanes, corrosion inhibitors, their mixtures) and polymer coatings decreased the rate of both equal-rate and local anodic dissolution of the metal. Because of this, it can be expected with high probability that the studied modifiers will also inhibit the corrosion cracking of carbon steel.

The corrosion and mechanical tests showed that the selected modifiers and inhibiting mixtures were capable of both decreasing the total affinity of the metal for the SCC (by the results of the SSRTs) and the rate of the corrosion crack development.

Figure 13 presents the results of the SSRTs in a pure buffered soil electrolyte (Fig. 13a) and with the addition of hydrogen sulfide (Fig. 13b), a known SCC activator.

It can be seen from Fig. 13 that introducing modifiers into the test solution leads to the inhibition of the SCC (the value of the contraction of the sample upon the introduction of modifiers into the solution is smaller than in the background solution). This inhibitory effect also manifests itself upon adding sodium sulfide which is an SCC promotor $[39,40]$ into the test solution (Fig. 13b, background). Moreover, the intro- (a)

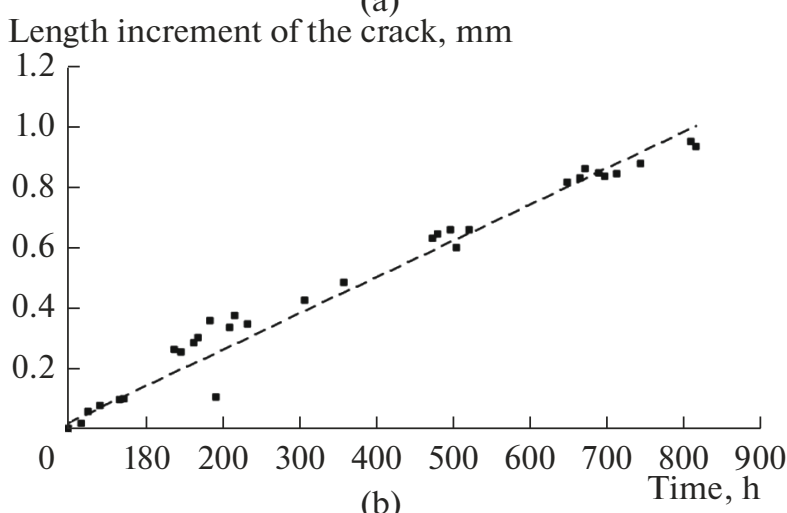

Length increment of the crack, $\mathrm{mm}$

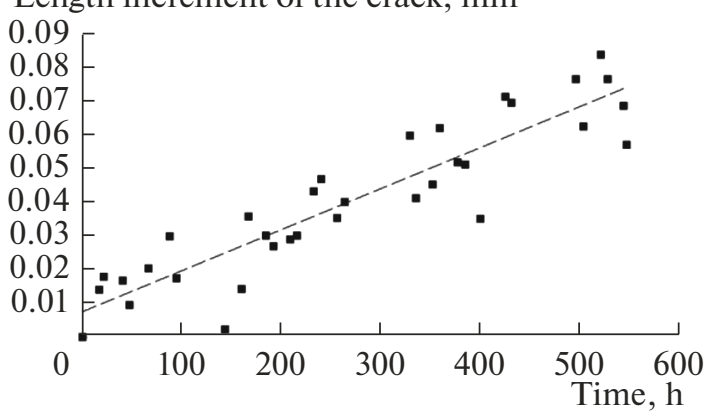

Fig. 14. Dependence of the length increment of the crack in the sample on the time in the background solution $(\mathrm{pH}$ of 5.5) containing $1 \mathrm{mM} \mathrm{Na} \mathrm{S}_{2} \mathrm{~S}$ (a) without additions and (b) with the addition of $1.7 \mathrm{~g} / \mathrm{L}$ ODA.

duction of individual organosilanes or corrosion inhibitors into the solution does not provide inhibiting efficiency as high as in the case of addition of a corrosion inhibitor + organosilane mixture into the solution.

Figure 14 presents the examples of the measurement of the rate of crack growth in the process of the tests with a static load. Thus, the values of the rate of crack growth in the background electrolyte with the addition of hydrogen sulfide were $1.2 \times 10^{-3} \mathrm{~mm} / \mathrm{h}$ (Fig. 14a). The introduction of a mixture of ODA and VTMS into the solution leads to a decrease in the rate of crack growth by almost an order of magnitude, and it is $1.21 \times 10^{-4} \mathrm{~mm} / \mathrm{h}$ (Fig. 14b).

In addition to the effect of the modification of polymer and paint coatings on the electrochemical behavior of steel, the corrosion of steel under the modified coating was also studied. Figure 15 shows the photographic images of the surface of the samples after conducting corrosion tests in a climatic chamber for 10 days. It has been found that equal-rate corrosion without clearly pronounced local corrosion damage sites is observed on the surface of the samples without the modification (Fig. 15a). The fraction of the damaged surface was $43 \%$ (Table 7). Coatings with the addition of BTA or silanes decelerate the corrosion, but, here, significant local damage sites are observed. The area of the damaged surface was 9,17 , and $7 \%$ 
(a)

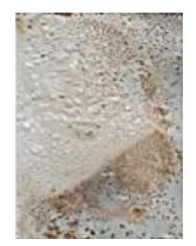

$10 \mathrm{~mm}$ (b)

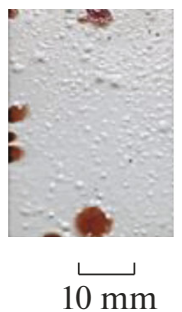

(e)

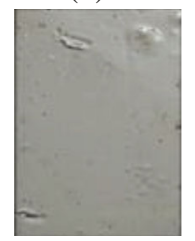

$\longrightarrow$

$10 \mathrm{~mm}$ (c)

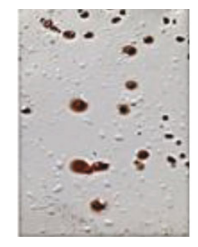

$10 \mathrm{~mm}$

(f)

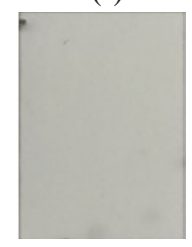

$10 \mathrm{~mm}$ (d)

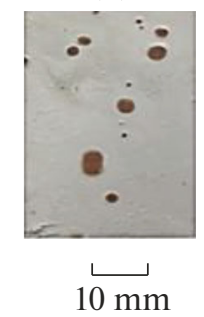

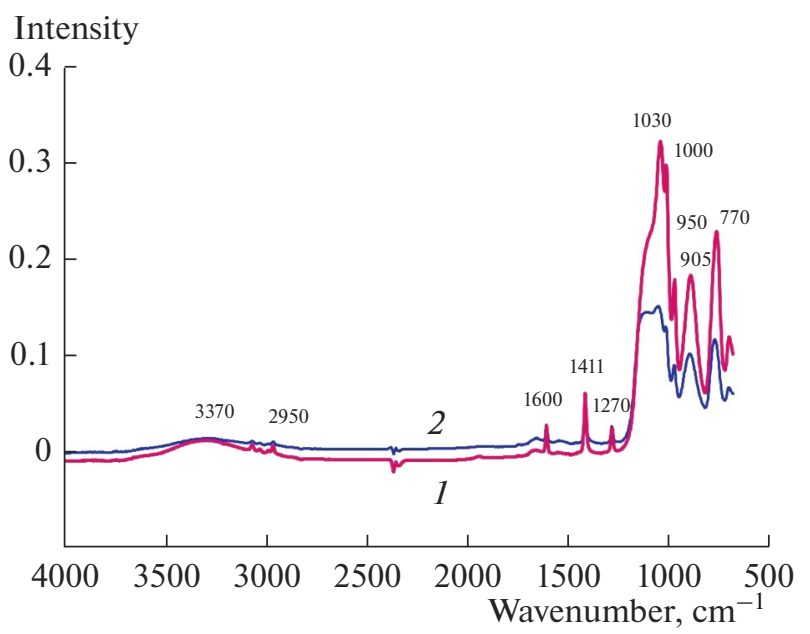

Fig. 16. Fourier-transform IR spectra of the surface of carbon steel treated with the (1) $1 \%$ aqueous solution of VTMS and (2) aqueous extract from the bitumen-polymer primer modified with vinylsilane. The extraction time is $\mathbf{5 0}$ days, room temperature.

$0.8 \%$, and with a mixture of BTA and DAS, $0.1 \%$ (Table 7). This indicates a synergism of the actions of the components of the mixture; i.e., the effect of the action of the mixture significantly exceeds the effect of each of the components of this mixture. The synergistic effect can be seen in the formation of a compact surface nanolayer strongly bound to the metal surface.

It is known that, in the case of operation of underground structures, corrosion processes mainly occur under the detached polymer coating, under which the electrochemical protection does not work. Because of this, to decrease the rate of corrosion of the metal under the coating, it is necessary that the molecules of the corrosion modifiers inhibitors migrate from the bulk of the polymer to the interface and exit into the electrolyte that is accumulated between the detached coating and the metal in the process of operation. To determine the mobility of the inhibitor molecules in the bulk of the polymer and evaluate the possibility of the exit of the inhibitor into the underfilm electrolyte in the case of the detachment of the coating by IR spectroscopy, the presence of the components of the modified coating, in particular, vinyl-containing silane, on the metal surface after the exposure of the metal in the solution of the aqueous extract from the modified coating was analyzed. Figure 16 shows the Fourier-transform IR spectra of the surface of steel treated with an aqueous solution of VTMS with a concentration of $1 \%$ (curve 1 ) and an aqueous extract of a Dekom-Gaz inhibited bitumen-polymer primer (curve 2). Coinciding bands can be seen in both curves in the figure, which indicates the exit of VTMS from the bulk of the polymer coating into the solution. The IR spectrum of the aqueous extract of the inhibited primer contains a series of bands assigned to the vinylsiloxane layer being formed upon the hydrolysis and polycondensation of the VTMS molecules on the sur- 


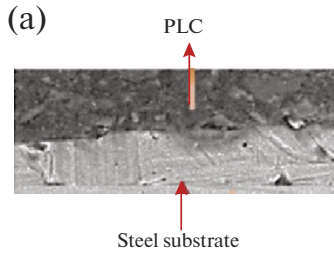

(c)
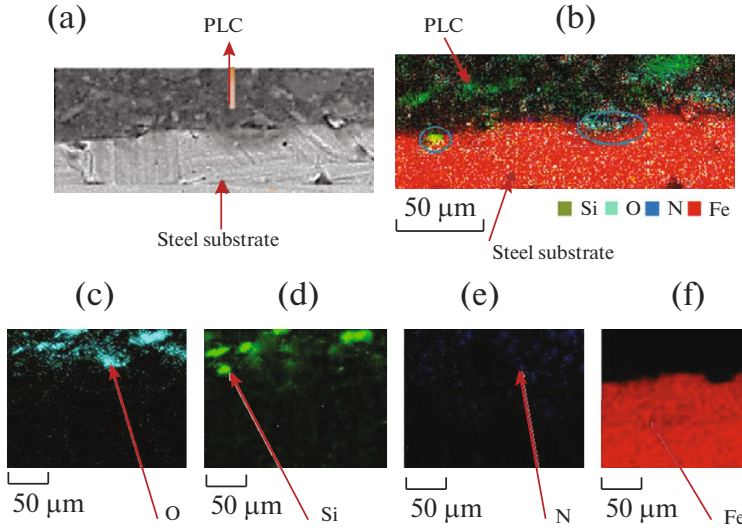

(e)

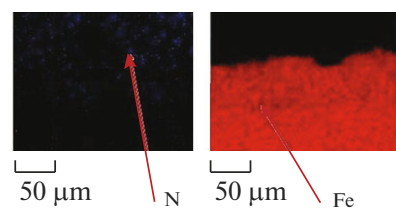

Fig. 17. Surface of the steel/styrene-acrylic dispersion (PLC) interface: (a) electronic photographic image of the metal/PLC interface, the PLC is modified with a mixture of VTMS + BTA; (b) color mapping of the metal/PLC interface, the PLC is modified with a mixture of BTA + VTMS; (c) concentration of oxygen at the metal/PLC interface, the PLC is modified with a mixture of BTA + VTMS; (d) concentration of silicon at the metal/PLC interface, the PLC is modified with a mixture of BTA + VTMS; (e) concentration of nitrogen at the metal/PLC interface, the PLC is modified with a mixture of BTA + VTMS; and (f) concentration of iron at the metal/PLC interface, the PLC is modified with a mixture of BTA + VTMS. Elemental analysis is performed by the EMF method.

face. Thus, the intense bands near 1030 and $1000 \mathrm{~cm}^{-1}$ lie in the region of vibrations of the $\mathrm{Si}-\mathrm{O}-\mathrm{Si}$ group [43], while the band at $905 \mathrm{~cm}^{-1}$ corresponds to the vibrations of the bridging oxygen atom in the $\mathrm{Si}-\mathrm{O}-\mathrm{Si}$ fragment. The bands at 1411 and $1600 \mathrm{~cm}^{-1}$ lie in the regions close to the vibrations of the $-\mathrm{CH}=\mathrm{CH}_{2}$ bond; those at $2950 \mathrm{~cm}^{-1}$, to the vibrations of the $\mathrm{CH}_{2}$ bonds of the vinyl group; and the band at $1270 \mathrm{~cm}^{-1}$, to the vibrations of the $\mathrm{Si}-\mathrm{CHCH}_{2}$ fragment [44]. The band at $770 \mathrm{~cm}^{-1}$ corresponds to the vibrations of the silicon-carbon bonds [45]. The wide but low-intensity band at about $3370 \mathrm{~cm}^{-1}$ lies in the region of vibrations of the $\mathrm{OH}$ group of the $\mathrm{Si}-\mathrm{OH}$ fragment [44]. In addition, a band lying in the region of $950 \mathrm{~cm}^{-1}$ has been found in the spectrum that is assigned to the vibrations of the surface $-\mathrm{Fe}-\mathrm{O}-\mathrm{Si}-$ groups [45].

The analysis of the spectra makes it possible to determine the nature of the chemical processes occurring on the surface of steel during the adsorption of VTMS from the underfilm electrolyte. Thus, the first stage of the process is the hydrolysis of the vinylsilane molecules $\mathrm{CH}_{2}=\mathrm{CH}-\mathrm{Si}\left(\mathrm{OC}_{2} \mathrm{H}_{5}\right)_{3}$ with the formation of vinylsilanol $\mathrm{CH}_{2}=\mathrm{CH}-\mathrm{Si}(\mathrm{OH})_{3}$ because no bands corresponding to the vibrations of the $\mathrm{Si}-\mathrm{O}-\mathrm{C}$ groups were detected in the spectrum, but, at the same time, bands corresponding to $\mathrm{Si}-\mathrm{OH}$ groups were observed. This indicates the absence of unhydrolyzed VTMS molecules on the surface. The appearance of the band at about $950 \mathrm{~cm}^{-1}$ that corresponds to the vibrations of $-\mathrm{Fe}-\mathrm{O}-\mathrm{Si}$ in the spectrum indicates the presence of a chemical interaction of the VTMS molecules and hydroxyl groups on the metal surface. Thereafter, the adjacent adsorbed molecules enter a polycondensation reaction to form bridging $\mathrm{Si}-\mathrm{O}-\mathrm{Si}$ bonds resistant to hydrolysis, which is evidenced by the presence of bands at about 1030, 1000, and $905 \mathrm{~cm}^{-1}$.

Therefore, the IR study showed that VTMS is capable of not only exiting the coating into the underfilm electrolyte, but also adsorbing on the surface of pipe steel to form strong surface bonds.

Figure 17 presents the electronic photographic images and color mapping of the metal/styreneacrylic dispersion (PLC) interface, while Table 8 presents the distribution of the elements at the metal/PLC interface for both the unmodified coating and the PLC modified with a mixture of VTMS and BTA. It can be seen from the micrographs that the addition of a mixture of BTA and organosilane into the PLC (Fig. 17a) provides good wetting of the metal surface with the polymer, i.e., the coating uniformly adjoins the surface of the metallic substrate, and no cracks are recorded in the layer adjacent to the surface. The study of the metal/polymer interface, where the polymer is a PLC modified with a mixture of BTA and VTMS, showed that oxygen and silicon were concentrated in the polymer layer with a thickness of 8-10 nm near the surface (Figs. 17c, 17d), and an increase in oxygen and silicon was observed in the modified PLC in comparison with the unmodified PLC, which may indicate the migration of the organosilane molecules from the bulk of the polymer to the metal surface and occurrence of the polycondensation reaction in the nearsurface layer, while fixed oxygen is a part of the $\mathrm{Si}-\mathrm{O}-$ Si fragments.

Moreover, sites of concentration of silicon (Fig. 17b) (they are denoted by a blue ring in the figure) and nitrogen (they are denoted by a blue oval in the figure) are found directly on the metal surface. It is likely that the nitrogen molecules present in the composition of the BTA molecules (Fig. 1) diffuse from the bulk of the polymer coating to the interface and interact with the surface, thus providing an increase in the adhesion of the PLC to the metal.

Table 8. Elemental composition of a pure water-diluted PLC and its mixture in the inhibiting composition at the metal/polymer interface

\begin{tabular}{l|c|c|c|c|c}
\hline \multirow{2}{*}{ System under study } & \multicolumn{5}{c}{ Distribution of elements, wt \% } \\
\cline { 2 - 6 } & $\mathrm{Fe}$ & $\mathrm{C}$ & $\mathrm{Si}$ & $\mathrm{N}$ & $\mathrm{O}$ \\
\hline $\mathrm{L}-9930$ & 83.8 & 7.8 & - & - & 8.4 \\
$\mathrm{~L}-9930+$ VTMS + BTA & 53.2 & 8.9 & 21.2 & 4.1 & 12.6 \\
\hline
\end{tabular}




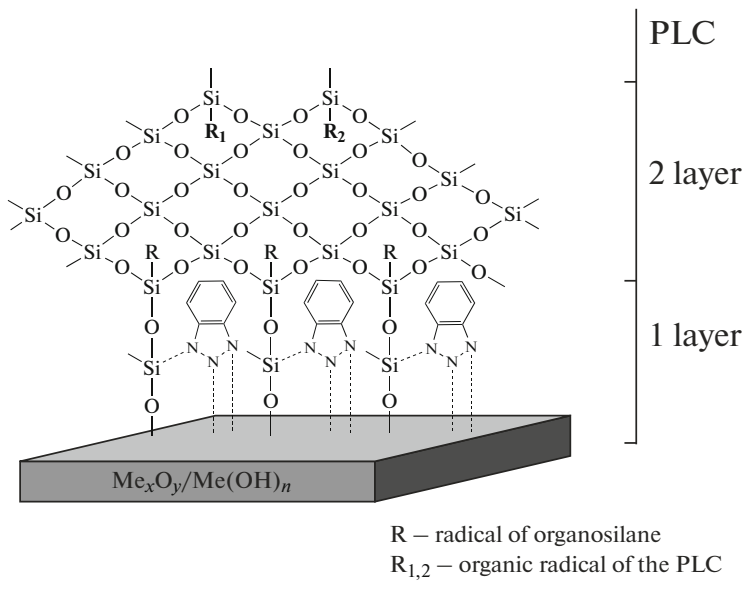

Fig. 18. Scheme of the structure of the polymer-like protective intermediate layer at the metal/PLC interface.

Based on the results of the performed tests, the following model of formation of the polymer-like film at the metal/PLC interface has been proposed (Fig. 18). As is shown in Fig. 18, the surface film being formed is two-layer. The first, siloxane-azole, layer is strongly bound to the metallic surface. The thickness of this layer does not exceed 1-2 $\mathrm{nm}$. The formation of the second layer located over the first layer occurs due to the siloxane groups of silane that bind to the organic radicals of the PLC to form structures similar to the interpenetrating polymer networks [46], which provide an increase in the adhesion of the coating. The thickness of the second layer is $35-40 \mu \mathrm{m}$.

Since the main protective characteristic of insulation materials on gas pipelines and other structures is the high adhesive strength of the coating and its retention under the action of the environment, principally the action of an electrolyte and a cathodic potential, the effect of the modification on the adhesive characteristics of the bitumen-polymer coating has been studied. Figure 19 and Table 9 present the results of the measurement of the adhesive strength of a Dekom bitumen-polymer coating (BPC); Fig. 20, of the water resistance of the BPC; and Table 10, of the resistance of the BPC to cathodic detachment. Table 11 presents the values of the adhesive strength of the

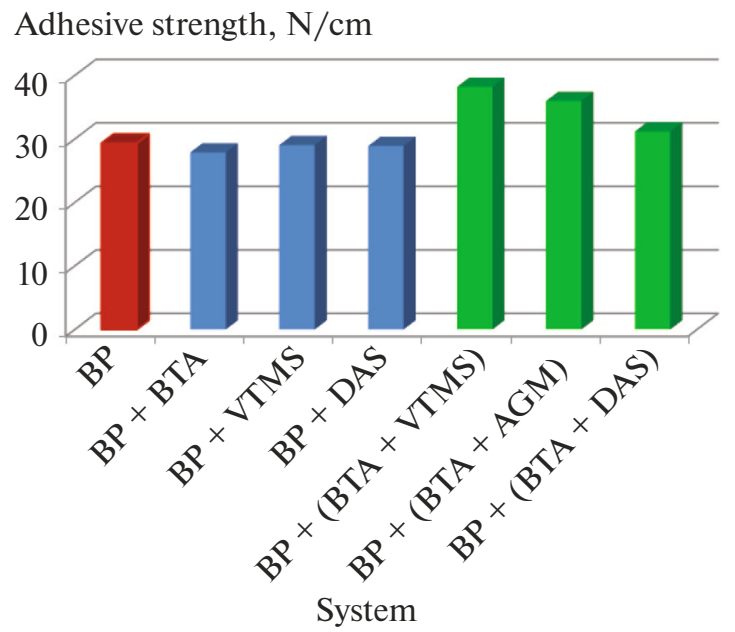

Fig. 19. Adhesive strength in the case of separation at an angle of $180^{\circ}$ of unmodified (BP column) and modified Dekom bitumen-polymer primer.

unmodified and modified styrene-acrylic dispersions (PLC).

It can be seen from Figs. 19 and 20 and Tables 911 that the polymer and paint coatings modified with organosilanes, a corrosion inhibitor, and mixtures thereof exhibited adhesive characteristics comparable to and exceeding the characteristics of the unmodified coatings. In addition, it should be noted that an adhesive character of the separation of the coating from the metal surface was observed in the case of the unmodified coatings. The modification of the coatings leads to a change in the character of separation; thus, it becomes mixed adhesion-cohesion, which indicates that the strength of the surface-coating bond is higher than the cohesive strength of the coating. The obtained results show that the modification of the coating will not only make it possible to inhibit the development of equal-rate and local corrosion (including SCC) on the metal, but also increase the adhesion of the coating, which may prolong its failurefree operating period.

Figure 21 presents the results of the measurements of the adhesive strength of the bitumen-polymer coating modified with organosilanes and a corrosion inhibitor-ODA and their mixture. It can be seen from

Table 9. Results of the tests of a Dekom coating with different modifiers for resistance to cathodic detachment, $3 \% \mathrm{NaCl}$, $-1.1 \mathrm{~V}(\mathrm{NHE}), 1000 \mathrm{~h}$

\begin{tabular}{c|l|c}
\hline Nos. & \multicolumn{1}{c|}{ System } & Area of the detached coating, $\mathrm{cm}^{2}$ \\
\hline 1 & Unmodified BP & 9.77 \\
2 & BP + (BTA + VTMS) & 6.57 \\
3 & BP + (BTA + AGM) & 7.10 \\
4 & BP + BTA & 9.5 \\
5 & BP + VTMS & 9.9 \\
6 & BP + AGM & 10.15 \\
5 & BP" + DAS & 10.19 \\
5 & BP + (BTA + DAS $)$ & 9.6 \\
\hline
\end{tabular}


Adhesive strength, $\mathrm{N} / \mathrm{cm}$ of the width

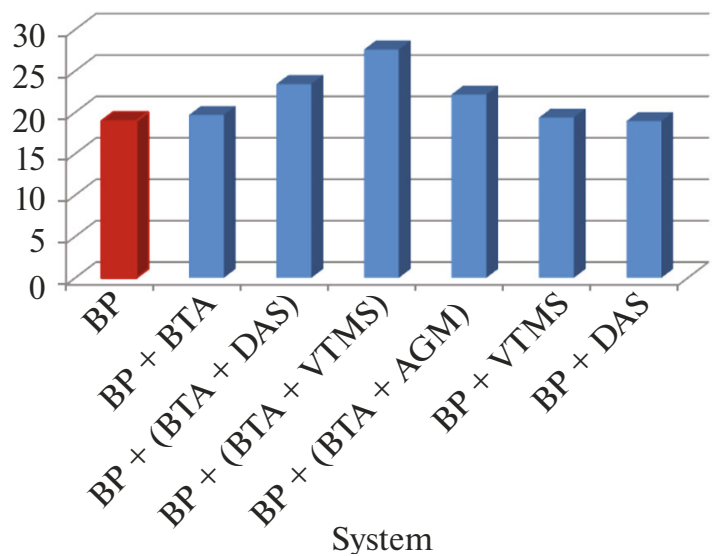

Fig. 20. Adhesive strength in the case of separation at an angle of $180^{\circ}$ of a Dekom bitumen-polymer primer after exposure in distilled water for $1000 \mathrm{~h}$.

the figure that the modification of the coating with a mixture of the corrosion inhibitor and organosilane turns out to be more efficient than the modification of the coating with individual organosilane and an individual corrosion inhibitor.

It can be noted based on the results of comprehensive tests that mixtures of a corrosion inhibitor (BTA or ODA) with organosilanes are the most efficient for improving the anticorrosion properties of coatings. The execution of bench adhesion tests at the testing facility of the manufacturer of the coating (Fig. 9) showed (Table 12) that the modification of the coating by the introduction of BTA or VTMS into the bulk of the polymer somewhat decreased the adhesion of the bitumen-polymer coating applied onto a section of a pipe; however, this decrease is small and significantly
Adhesive strength, $\mathrm{N} / \mathrm{cm}$

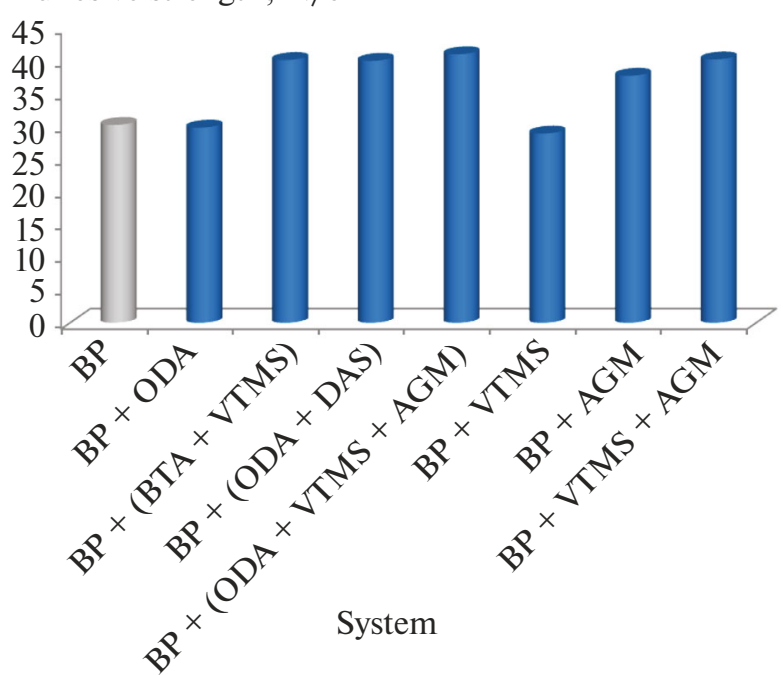

Fig. 21. Adhesive strength in the case of separation at an angle of $180^{\circ}$ of the unmodified (BP column) and modified Dekom bitumen-polymer primer.

exceeds the values recommended by the normative documents for the coatings used for pipelines [47]. The introduction of a mixture of BTA with vinyl-containing silane into the bulk of the polymer primer leads to an increase in the adhesion of the coating (Table 12), which confirms the results of the laboratory adhesion studies.

\section{CONCLUSIONS}

1. It has been shown that mixtures of 1,2,3-benzotriazole (BTA) with vinyltrimethoxysilane (VTMS) or aminoethylaminopropyltrimethoxysilane-diami-

Table 10. Character of separation of unmodified steel and steel modified with the bitumen-polymer primer (BP) from the surface

\begin{tabular}{c|l|l}
\hline Nos. & \multicolumn{1}{|c|}{ System } & \multicolumn{1}{|c}{ Character of separation } \\
\hline 1 & Bitumen-polymer primer & $60 \%$ cohesion by primer, \\
& without inhibiting additives (BP) & $40 \%$ adhesion from metal \\
\hline 6 & BP + VTMS & $90 \%$ cohesion by primer, \\
& & $10 \%$ adhesion from metal \\
\hline 7 & BP + 1(BTA + VTMS) & $100 \%$ cohesion by primer \\
\hline 8 & BP + (BTA + DAS) & $100 \%$ cohesion by primer \\
\hline 9 & BP + BTA & $80 \%$ cohesion by primer, \\
& & $20 \%$ adhesion from metal \\
\hline 10 & BP + (BTA + AGM) & $90 \%$ cohesion by primer, \\
& & $10 \%$ adhesion from metal \\
\hline 11 & BP + MPTMS & $50 \%$ cohesion by primer, \\
& & $50 \%$ adhesion from metal \\
\hline 12 & BP + BTESE & $30 \%$ cohesion by primer, \\
& & $60 \%$ adhesion from metal \\
\hline 13 & BP + AGM & $95 \%$ cohesion by primer, \\
& & $5 \%$ adhesion from metal \\
\hline
\end{tabular}


Table 11. Results of the adhesion tests of the styrene-acrylic dispersion (PLC) with the modifying additives: A is the adhesive character of separation, and $\mathrm{C}$ is the cohesive character of separation

\begin{tabular}{c|l|c|l}
\hline No. & \multicolumn{1}{|c|}{ System } & Adhesive strength, N/cm & \multicolumn{1}{|c}{ Character of separation } \\
\hline 1 & PLC & $234 \pm 10$ & $100 \%$ adhesion from metal \\
2 & PLC + BTA & $250 \pm 10$ & $40 \%$ cohesion by primer, \\
3 & PLC + VTMS & $255 \pm 10$ & $60 \%$ adhesion from metal \\
& & $35 \%$ cohesion by primer, \\
4 & PLC + DAS & $265 \pm 10$ & $65 \%$ adhesion from metal \\
5 & PLC0 + (BTA + VTMS) & $270 \pm 10$ & $35 \%$ cohesion by primer, \\
6 & L $-9930+$ BTA + DAS & $290 \pm 10$ & $65 \%$ adhesion from metal \\
\hline
\end{tabular}

Table 12. Results of the bench tests of a Dekom bitumenpolymer coating (BP) with different modifiers

\begin{tabular}{c|l|c}
\hline No. & \multicolumn{1}{|c|}{ System } & Adhesive strength, N/cm \\
\hline 1 & Unmodified BP & 74 \\
2 & BP + (BTA + VTMS) & 91 \\
3 & BP + BTA & 53 \\
4 & BP + + VTMS & 73 \\
\hline
\end{tabular}

nosilane (DAS) inhibit the local dissolution and underfilm corrosion of carbon steel, and the potential of local depassivation shifts by $0.3-0.4 \mathrm{~V}$. Here, compact polymer-like layers are formed on the surface of steel, which are strongly bound to the metal surface.

2. Corrosion and mechanical tests of the samples of pipe steels with different types of inhibiting compositions have been performed. The effect of the inhibitors on the crack growth under static load in a model soil electrolyte (pH of 5.5) and crack resistance of steel in the case of slow tension in an NS-4 model underfilm electrolyte ( $\mathrm{pH}$ of 7.0) has been evaluated. The tests were performed in media free from and containing hydrogen sulfide. It has been shown that mixtures of corrosion inhibitors with organosilanes demonstrate the best inhibiting properties.

3. Comparative laboratory and bench tests for adhesive strength, water resistance, and resistance to cathodic detachment of the adhesive junctions obtained upon applying modified polymer and paint coatings onto the surface of steel have been performed. It has been found that the introduction of a mixture of organosilane and a corrosion inhibitor improves the adhesive properties of polymer and paint coatings.

\section{FUNDING}

This work was financially supported by Basic Research Program of the Presidium of the Russian Academy of Sciences no. 4P "Relevant Problems of Surface Physicochemistry and Creation of Novel Composite Materials.”

\section{OPEN ACCESS}

This article is distributed under the terms of the Creative Commons Attribution 4.0 International License (http:// creativecommons.org/licenses/by/4.0/), which permits unrestricted use, distribution, and reproduction in any medium, provided you give appropriate credit to the original author(s) and the source, provide a link to the Creative Commons license, and indicate if changes were made.

\section{REFERENCES}

1. Kurz, M., Handbook of Environmental Degradation of Materials, New York: William Andrew, 2005.

2. Schmitt, G., Schütze, M., Hays, G.F., Burns, W., Han, E.-H., Pourbaix, A., and Jacobson, G., Global Needs for Knowledge Dissemination, Research, and Development in Materials Deterioration and Corrosion Control, World Corrosion Organization, 2009, p. 7.

3. McCafferty, E., Introduction to Corrosion Science, Heidelberg: Springer, 2010, p. 4.

4. Vogelsang, J.A., in Self-Healing Properties of New Surface Treatments, Fedrizzi, L., Furbeth, W., and Montemor, F., Eds., Leeds: Maney Publ., 2011, pp. 1-11.

5. Safronchik, V.I., Zashchita podzemnykh truboprovodov antikorrozionnymi pokrytiyami (Protection of Underground Pipe-Lines with the Help of Anticorrosive Coatings), Leningrad: Stroiizdat, 1977, p. 4.

6. Cheng, Y.F., Stress Corrosion Cracking of Pipelines, Wiley, 2013.

7. Godovoi otchet o deyatel'nosti federal'noi sluzhby po ekologicheskomu, tekhnologicheskoтu i atomnomu nadzoru $v 2018$ godu (Annual Report on the Activities of Federal Service for Environmental, Technological, and Nuclear Supervision in 2018 Year), Moscow, 2019.

8. Sastri, V.S., Challenges in Corrosion. Costs, Causes, Consequences, and Control, Wiley, 2015, p. 97.

9. Knudsen, O. and Forsgren, A., Corrosion Control Through Organic Coatings, Boca Raton, FL: CRC Press, 2017, p. 256.

10. Kendig, M. and Mills, D.J., Prog. Org. Coat., 2017, vol. 102, pp. 53-59.

11. Tiwari, A., Rawlins, J., and Hihara, L.H., Intelligent Coatings for Corrosion Control, Amsterdam: Elsevier, 2015.

12. Wang, L.K., Hang, Y.-T., and Shammas, N.K., Physicochemical Treatment Processes, Totowa, NJ: Humana Press, 2005, p. 151.

13. Hazardous Substances and Human Health: Exposure, Impact and External Cost Assessment at the European Scale, Nriagu, O., Ed., Amsterdam: Elsevier, 2006.

14. White Paper Strategy for a Future Chemical Policy of the Commission of the European Communities. Directive 
2011/65/EU of the European Parliament and of the Council, Brussels, 2011.

15. Buchhet, R.G., Guan, H., Mahajanam, S., and Wong, F., Prog. Org. Coat., 2003, vol. 47, pp. 174-182.

16. Arkles, B., Silane Coupling Agents. Connecting Across Boundaries, Morrisville, PA: Gelest, 2014.

17. Petrunin, M.A., Gladkikh, N.A., Maleeva, M.A., Maksaeva, L.B., and Yurasova, T.A., Int. J. Corros. Scale Inhib., 2019, vol. 8, no. 4, pp. 882-907.

18. Petrunin, M.A., Maksaeva, L.B., Yurasova, T.A., Terekhova, E.V., Kotenev, V.A., Kablov, E.N., and Tsivadze, A.Yu., Prot. Met. Phys. Chem. Surf., 2012, vol. 48, no. 6, pp. 656-664.

19. Petrunin, M.A., Gladkikh, N.A., Maleeva, M.A., Maksaeva, L.B., Kostina, Yu.V., Shapagin, A.V., Yurasova, T.A., Kotenev, V.A., and Tsivadze, A.Yu., Prot. Met. Phys. Chem. Surf., 2019, vol. 55, no. 5, pp. 895902.

20. Silicone Surface Science, Owen, M.J. and Dvornic, P.R., Eds., Heidelberg: Springer, 2012, p. 281.

21. Palanivel, V., Zhu, D., and van Ooij, W.J., Prog. Org. Coat., 2003, vol. 47, pp. 384-392.

22. Aramaki, K. and Shimura, T., Corros. Sci., 2010, vol. 52, pp. 2766-2772.

23. Avdeev, Yu.P., Karpov, V.A., Maksaeva, L.B., and Petrunin, M.A., Int. J. Corros. Scale Inhib., 2014, vol. 3, no. 3, pp. 198-203.

24. Kelly, R.G., Scully, J.R., Shoesmith, D.W., and Buchheit, R.G., Electrochemical Techniques in Corrosion Science and Engineering, New York: Marcel Dekker, 2002.

25. Heitz, E., DC Electrochemical Methods, in Analytical Methods in Corrosion Science and Engineering, Marcus, P. and Mansfeld, F., Eds., Boca Raton, FL: CRC Press, 2006, pp. 435-462.

26. Szklarska-Smialowska, Z., Pitting and Crevice Corrosion, NACE Int., 2005, p. 5.

27. Kuznetsov, Yu.I., Usp. Khim., 2004, vol. 73, no. 1, pp. 79-93.

28. Gladkikh, N., Makarychev, Yu., Maleeva, M., Petrunin, M., Maksaeva, L., Rybkina, A., Marshakov, A., and Kuznetsov, Yu., Prog. Org. Coat., 2019, vol. 132, pp. 481-489.

29. ISO no. 8407:2009: Corrosion of Metals and Alloys-Removal of Corrosion Products from Corrosion Test Specimens, 2009.

30. ASTM D610-08: Standard Practice for Evaluating Degree of Rusting on Painted Steel Surfaces, West Conshohocken, PA: ASTM Int., 2019.

31. Bogdanov, R., Marshakov, A., Ignatenko, V., Ryakhovskikh, I., and Bachurina, D., Corros. Eng., Sci. Technol., 2017, vol. 52, no. 4, pp. 294-301.
32. Sojka, J., Jerome, M., Sozanska, M., Vanova, P., Rytırova, L., and Jonsta, P., Mater. Sci. Eng., A, 2008, vol. 480, pp. 237-243.

33. Marichev, V.A., J. Solid State Electrochem., 2012, vol. 16 , no. 12 , pp. 3675-3681.

34. Gol'dberg, A.S., Energetika $v$ akronimakh i sokrashcheniyakh. Anglo-russkii slovar' (Power Engineering in Acronyms and Abbreviations. English-Russian Dictionary), Moscow: BINOM. Laboratoriya Znanii, 2015, p. 390 .

35. Ignatenko, V.E., Kuznetsov, Yu.I., Arabei, A.B., Igoshin, R.V., Bogdanov, R.I., and Marshakov, A.I., Int. J. Corros. Scale Inhib., 2013, vol. 2, no. 4, p. 318.

36. GOST (State Standard) no. 1497-84: Metals. Methods of Tension Test, Moscow: Standartinform, 1986.

37. ASTM D 3330/D 3330M-02: Standard Test Method for Peel Adhesion of Pressure-Sensitive Tap. Test Method A Single-Coated Tapes at $180^{\circ}$ Angle, West Conshohocken, PA: ASTM Int., 2004.

38. GOST (State Standard) no. 9.602-2016: Unified System of Corrosion and Ageing Protection. Underground Constructions. General Requirements for Corrosion Protection, Moscow: Standartinform, 2016.

39. Stress Corrosion Cracking. Theory and Practice, Raja, V.S. and Shoji, T., Eds., Oxford: Woodhead Publ., 2011.

40. Marshakov, A.I., Ignatenko, V.E., Bogdanov, R.I., and Arabey, A.B., Corros. Sci., 2014, vol. 83, pp. 209-216.

41. Ivanov, E.S., Ingibitory korrozii metallov v kislykh sredakh. Spravochnik (Inhibitors of Metals Corrosion in Acidic Media. Handbook), Moscow: Metallurgiya, 1986.

42. Goldade, V.A., Pinchuk, L.S., Makarevic, A.V., and Kestelman, V.N., Plastics for Corrosion Inhibition, Berlin: Springer, 2005.

43. Flamini, D.O., Trueba, M., and Trasatti, S.P., Prog. Org. Coat., 2012, vol. 74, pp. 302-310.

44. Franquet, A., Terryn, H., and Vereecken, J., Thin Solid Films, 2003, vol. 441, pp. 259-269.

45. Chaneac, C., Tronc, E., and Jolivet, J.P., J. Mater. Chem., 1996, vol. 6, pp. 1905-1911.

46. Thomas, S., Grande, D., Cvelbar, U., Raju, V.S.N., Narayan, R., Thomas, S.P., and Akhina, H., Microand Nano-Structured Interpenetrating Polymer Networks. From Design to Applications, Willey, 2016.

47. GOST (State Standard) no. 9.602-2016: Unified System of Corrosion and Ageing Protection. Underground Constructions. General Requirements for Corrosion Protection, Moscow: Standartinform, 2016.

Translated by E. Boltukhina 